\title{
ANÁLISE DO CRESCIMENTO DE UMA CULTIVAR DE BRAQUIÁRIA EM CULTIVO SOLTEIRO E CONSORCIADO COM CEREAIS ${ }^{1}$
}

\author{
TOMÁS DEAQUINO PORTES², SABRINAISABEL COSTA DE CARVALHO, \\ ITAMAR PEREIRA DE OLIVEIRA ${ }^{4}$ e JOÃO KLUTHCOUSKI ${ }^{5}$
}

\begin{abstract}
RESUMO - O objetivo deste trabalho foi avaliar o crescimento de braquiária (Brachiaria brizantha cv. Marandu), em consorciação com milho, sorgo, milheto e arroz, bem como da sua rebrota após a colheita dos cereais. A presença dos cereais provocou redução no número de perfilhos, índice de área foliar, massa seca total da parte aérea, massa seca das folhas verdes e dos colmos e taxa de crescimento na braquiária, até a colheita dos cereais. O número de perfilhos alcançou valores maiores do que os da braquiária solteira, após a colheita dos cereais. Os índices de área foliar da braquiária consorciada foram baixos, em comparação com os dos cereais, e a baixa competição, em cobertura foliar, favoreceu a boa produtividade de grãos das culturas. Aos 60-70 dias após a colheita dos cereais, a braquiária rebrotada possuía fitomassa semelhante à da solteira 70 dias após a emergência.
\end{abstract}

Termos para indexação: Brachiaria brizantha, renovação de pastagem, rebrota, taxa de crescimento, consorciação, cultivo de cereais, grãos, produtividade.

\section{GROWTH ANALYSIS OF A BRACHIARIA CULTIVAR SOLE AND INTERCROPPED WITH CEREALS}

\begin{abstract}
The aim of this work was to evaluate the growth of brachiaria (Brachiaria brizantha cv. Marandu) intercropped with maize, sorghum, pearl millet and rice and its regrowth after cereals harvest. The presence of cereals caused reduction of tillers number, foliar area index, total dry matter of leaves, dry matter of green leaves and stems, and growth rate of brachiaria up to harvest of cereals. Number of tillers $\mathrm{m}^{-2}$ reached higher values than those of sole cropped brachiaria after the cereals harvest. The leaf area indices of intercropped brachiaria were low, when compared to those of the cereals; and the low competition in the leaf area favoured the good grain yield of the crops. Sixty to seventy days after cereals harvest, brachiaria regrowth showed phytomass similar to that of sole cropped brachiaria 70 days after emergence.
\end{abstract}

Index terms: Brachiaria brizantha, pasture renovation, regrowth, growth rate, intercropping, cereal crops, grain, productivity.

\section{INTRODUÇÃO}

A maior parte do Cerrado brasileiro está localizada na Região Centro-Oeste. Nesta região, as pasta-

\footnotetext{
${ }^{1}$ Aceito para publicação em 6 de abril de 2000

${ }^{2}$ Eng. Agrôn., Dr., Universidade Federal de Goiás (UFG), Caixa Postal 131, CEP 74001-970, Goiânia, GO

E-mail: portes@icb1.ufg.br

${ }^{3}$ Eng. Agrôn., M.Sc., Embrapa-Centro Nacional de Pesquisa de Hortaliças, Caixa Postal 218, CEP 70359-970 Brasília, DF. Bolsista do CNPq

${ }^{4}$ Eng. Agrôn., Dr., Embrapa-Centro Nacional de Pesquisa de Arroz e Feijão (CNPAF), Caixa Postal 179, CEP 74001-970 Goiânia, GO. E-mail: itamar@enpaf.embrapa.br

${ }^{5}$ Eng. Agrôn., Dr., Embrapa-CNPAF.

E-mail: joaok@cnpaf.embrapa.br
}

gens cultivadas ocupavam, segundo estimativas feitas em 1994, de 45 a 50 milhões de hectares. Mais de $50 \%$ dessas pastagens já apresentavam, naquela época, algum processo de degradação, como: perda do vigor, da produtividade e da capacidade de recuperação natural (Macedo \& Zimmer, 1993; Macedo, 1995).

A recuperação das áreas degradadas por métodos tradicionais - preparo do solo e semeio de capins - é muito onerosa, em especial pela necessidade de correção da fertilidade.

A estratégia de renovação de pastagens mediante a consorciação de culturas de grãos com capins é uma alternativa viável. Ao conjunto de técnicas criadas ou adaptadas visando renovar as pastagens 
degradadas e produzir grãos simultaneamente, enfatizando sua auto-sustentação, denominou-se Sistema Barreirão (Kluthcouski et al., 1991; Oliveira et al., 1996).

Vários trabalhos realizados constataram a viabilidade do sistema do ponto de vista técnico e econômico (Kluthcouski et al., 1991; Portes et al., 1995; Oliveira et al., 1996; Yokoyama et al., 1998).

A redução apresentada quanto ao rendimento de grãos no sistema consorciado, em relação ao solteiro, não o inviabiliza, visto que vários outros fatores o beneficiam, em especial a pastagem renovada.

Mesmo com vários avanços na pesquisa sobre o sistema, questiona-se a intensidade com que cada cultura interfere no crescimento da forrageira, o modo pelo qual a pastagem se recupera após a colheita das culturas e quais as variações no crescimento da gramínea forrageira no cultivo consorciado, em relação ao solteiro.

Este trabalho teve como objetivos avaliar o efeito da presença dos cereais arroz, milho, sorgo e milheto no crescimento de uma cultivar de braquiária e quantificar o crescimento da rebrota da braquiária após a colheita dos cereais.

\section{MATERIAL E MÉTODOS}

O experimento foi instalado em uma área de pastagem degradada de Brachiaria decumbens, na Universidade Federal de Goiás, em Goiânia, GO, $16^{\circ} 41^{\prime} \mathrm{S}$ e $49^{\circ} 17^{\prime} \mathrm{W}$, altitude de $730 \mathrm{~m}$. A precipitação pluvial média mensal e as temperaturas máximas, mínimas e médias do ar são mostradas na Fig. 1.

O solo da área experimental é do tipo Latossolo Vermelho-Escuro. Após a aplicação de $2.500 \mathrm{~kg} \mathrm{ha}^{-1}$ de calcário, iniciou-se o preparo do solo. Foi feita uma gradagem com grade aradora, com a finalidade de triturar os restos vegetais da pastagem degradada e destruir os cupinzeiros. Depois, foi utilizado o arado de aiveca, com o objetivo de incorporar os restos de vegetais a uma profundidade de até 0,40 m, visando dificultar a brotação ou a germinação de sementes ali presentes.

Os tratamentos foram constituídos de braquiária (Brachiaria brizantha $\mathrm{cv}$. Marandu) em sistema de cultivo solteiro e consorciado com milho (Zea mays L., cv. AG 510), sorgo (Sorghum vulgaris, cv. AG 3001), milheto (Pennisetum americanum, cultivar indefinida, de porte médio, altura da copa, por ocasião da floração, em torno de $1,80 \mathrm{~m}$ ) e arroz (Oryza sativa cv. Douradão).
O plantio, realizado no dia 4 de dezembro de 1993, foi feito em faixas de aproximadamente $120 \mathrm{~m}$ de comprimento por $10 \mathrm{~m}$ de largura e cada faixa representou um tratamento. Dentro de cada faixa foram demarcadas quatro parcelas de $4 \mathrm{~m} \times 10 \mathrm{~m}$, onde foram feitas as coletas de amostras de plantas de braquiária e de plantas dos cereais.

As sementes de braquiária foram misturadas ao adubo e distribuídas mecanicamente, no sulco de plantio, na profundidade de 0,10 m. As de milheto foram distribuídas da mesma forma, pela dificuldade no seu manuseio, isto é, por serem pequenas e muito leves. As sementes das demais culturas, milho, sorgo e arroz, foram distribuídas a aproximadamente $0,03 \mathrm{~m}$ de profundidade, conforme se recomenda. $\mathrm{O}$ espaçamento utilizado entre as linhas das culturas de arroz, sorgo e milheto foi de $0,40 \mathrm{~m}$ e de $0,80 \mathrm{~m}$ entre as de milho. Entre as linhas de milho foi semeada uma adicional de braquiária, com espaços de 0,40 m entre linhas em todos os tratamentos.

Foi feita adubação de correção com a aplicação de $300 \mathrm{~kg} \mathrm{ha}^{-1}$ da fórmula 4-30-16, acrescidos de $30 \mathrm{~kg} \mathrm{ha}^{-1}$ de uma mistura de micronutrientes FTE BR 12 e $20 \mathrm{~kg} \mathrm{ha}^{-1}$ de sulfato de zinco. A adubação nitrogenada, em cobertura, foi feita 40 dias após a emergência das plantas, com $40 \mathrm{~kg} \mathrm{ha}^{-1} \mathrm{de} \mathrm{N}$ na forma de sulfato de amônio, aplicado mecanicamente junto à linha de plantio. As quantidades aplicadas de calcário e de fertilizantes seguiram recomendações constantes em informações de experimentos realizados anteriormente (Kluthcouski et al., 1991)

O experimento foi dividido em duas fases: a primeira, da emergência das plantas dos cereais, que se deu em torno dos cinco dias após o plantio, até as suas colheitas, realizadas manualmente (aos 102 dias após a emergência do milheto, sorgo e arroz, e aos 131 dias após a do milho). Após a colheita dos cereais foi feito um corte manual, a uma altura de $0,30 \mathrm{~m}$, somente na braquiária consorciada, simulando um corte involuntário como conseqüência de

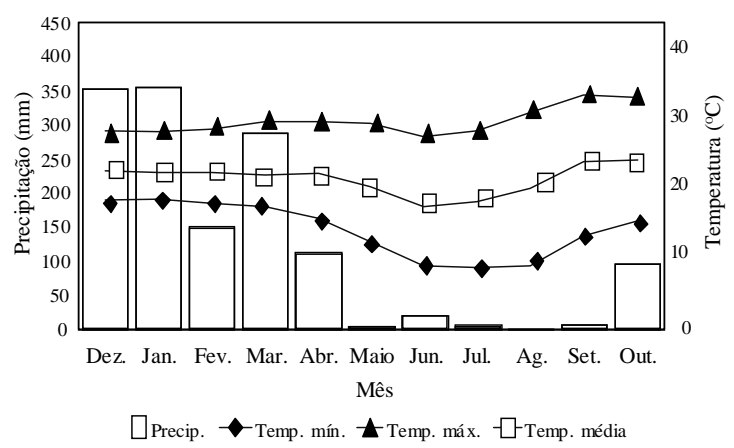

FIG. 1. Precipitação, temperaturas máxima, mínima e média, de dezembro de 1993 a outubro de 1994. 
uma colheita mecânica; a segunda fase, da colheita até a recuperação da fitomassa da braquiária, que se deu aproximadamente aos 181 dias após a emergência dos cereais (DAE)

Para análise do crescimento da braquiária, foram feitas amostragens aos 39, 47, 55, 70, 82, 90, 97, 117, 131, 151 e 181 dias após a emergência dos cereais. Em cada parcela, fora da área útil delimitada para se estimar a produção de grãos, e da bordadura, foram demarcados $2 \mathrm{~m}$ lineares, na linha de plantio, para a contagem do número de perfilhos da braquiária, sempre por ocasião das amostragens das plantas. As amostragens consistiam na coleta de duas plantas por parcela, introduzidas em tubos de PVC (de 1,0 m de comprimento $\times 0,10 \mathrm{~m}$ de diâmetro) com as raízes imersas em água, para evitar a murcha, e então transportadas para o laboratório

Nas plantas coletadas foram contados os perfilhos (perfilhos amostra ${ }^{-1}$ ), descartadas as raízes e separadas as folhas verdes e os colmos. Em seguida, mediu-se a área foliar em medidor eletrônico $\left(\mathrm{em} \mathrm{cm}^{2}\right)$, modelo LI $3100 \mathrm{da}$ LI-COR (Nebraska). As folhas verdes e os colmos foram colocados em sacos de papel, separadamente, e levados a secar em estufa com ventilação forçada a $65^{\circ} \mathrm{C}$ por 24 horas no início do experimento, e a $75^{\circ} \mathrm{C}$ durante 24 horas no final, como recurso para secar amostras volumosas

Foram estimadas as seguintes variáveis da braquiária solteira e consorciada: número de perfilhos (NP) $\mathrm{m}^{-2}$, índice de área foliar (IAF) $\left(\mathrm{m}^{-2}\right.$ de folhas $\mathrm{m}^{-2}$ de terreno), massa seca das folhas verdes e dos colmos, massa seca total da parte aérea (colmos + folhas)

O número de perfilhos $\mathrm{m}^{-2}$ foi calculado tomando-se por base o número de perfilhos por metro linear $\left(\mathrm{NP} \mathrm{m}^{-1}\right)$, dentro da linha de $2 \mathrm{~m}$ previamente demarcada, e dividindo-se esse valor pelo espaçamento entre linhas. Assim:

$\mathrm{NP} \mathrm{m}{ }^{-2}=\left(\mathrm{NP} \mathrm{m}^{-1}\right) \times$ [espaçamento $\left.(\mathrm{m})\right]^{-1}$

Os IAF foram estimados de acordo com a equação:

$\mathrm{IAF}=\left[\mathrm{NP} \mathrm{m}^{-1} \times \mathrm{AF}\right.$ amostra $] \times$ [espaçamento $\mathrm{x}$ perfilho $\left.\operatorname{amostra}^{-1} \times 10.000\right]^{-1}$,

sendo $\mathrm{AF}$ a área foliar da amostra $\left(\mathrm{cm}^{2}\right)$.

As massas secas das folhas verdes (MSFV) e dos colmos (MSC) foram estimadas utilizando-se a equação:

$\operatorname{MSFV}($ ou MSC $)=\left(\mathrm{NP} \mathrm{m}^{-1} \times \mathrm{MS}\right.$ amostra $) \times$ [espaçamento $\mathrm{x}$ perfilho amostra $\left.^{-1}\right]^{-1}$.

As estimativas das produções de grãos foram feitas colhendo-se os cereais em uma área útil de $4,8 \mathrm{~m}^{2}$ para o milheto e o sorgo, e de $6,4 \mathrm{~m}^{2}$ para o arroz e o milho.

\section{RESULTADOS E DISCUSSÃO}

\section{Primeira fase: da emergência das plantas até a co- Iheita das culturas}

Aos valores observados de IAF, massa seca total, massa seca das folhas verdes e massa seca dos colmos, em função do tempo (DAE), foram ajustadas equações matemáticas e feitos os testes de significância para as regressões, com programa computacional (Zullo Júnior \& Arruda, 1987); a equação que melhor se ajustou aos dados foi a do tipo polinomial exponencial quadrática:

$\mathrm{Y}=\mathrm{CEXP}\left(\mathrm{AX}+\mathrm{BX}^{2}\right)$,

onde $\mathrm{Y}$ é a variável dependente (descreve a variação do IAF, massa seca total, massa seca das folhas verdes e massa seca dos colmos em função do tempo), A, B e C os coeficientes da equação (Tabela 1) e X a variável independente (tempo em dias após a emergência).

Os ajustes, nos diferentes tratamentos, foram todos significativos quanto às variáveis mencionadas em função do tempo $(\mathrm{P}<0,05)$. Exceção para as variáveis IAF e MSFV x tempo no tratamento braquiária $\mathrm{x}$ sorgo, sendo $\mathrm{P}<0,10$.

Observou-se que, desde o início das amostragens das plantas para análise de crescimento, aos $39 \mathrm{DAE}$, houve competição, em maior ou menor intensidade, dos cereais com a braquiária. Essa competição, essencial para o êxito da técnica, resultou em menos perfilhos, menores IAF, menores ganhos de massa seca de folhas, colmos e total, da braquiária consorciada em relação à solteira. As sementes da braquiária foram distribuídas, juntamente com o fertilizante, a uma profundidade de $0,10 \mathrm{~m}$, retardando, por isso, em torno de cinco dias a emergência das plântulas e enfraquecendo-as (Oliveira et al., 1996) em relação às dos cereais, cujas sementes foram distribuídas a 0,03 m, exceto as do milheto. Enfraquecidas e sombreadas pelas plantas dos cereais, as da braquiária apresentaram crescimento lento, em especial por possuírem metabolismo $\mathrm{C}_{4}$ de fixação do $\mathrm{CO}_{2}$, característica que as fazem muito exigentes por luz. Isto proporcionou aos cereais completarem o seu ciclo e produzirem satisfatoriamente. Embora as sementes do milheto também tenham sido misturadas ao adubo, a emergência das plântulas se deu praticamente na mesma data dos demais cereais. 


\section{Índices de área foliar (IAF)}

A braquiária solteira apresentou, aos 70 dias, um IAF de $3,62 \mathrm{~m}^{2}$ de folhas $\mathrm{m}^{-2}$ de terreno, e de $6,51 \mathrm{~m}^{2}$ aos 97 dias após a emergência. Somente aos 117 dias alcançou IAF máximo (Fig. 2). Pelo fato de a quantidade de folhas senescentes ter aumentado substancialmente em relação às emergentes, o IAF começou a declinar após os 117 dias, reduzindo-se a $4,8 \mathrm{~m}^{2}$ aos 151 dias. A consorciada com arroz atingiu, aos 70 dias, $1,46 \mathrm{~m}^{2} \mathrm{e}$ com o milho $1,47 \mathrm{~m}^{2}$, alcançando valores máximos, aos 82 dias, de $1,73 \mathrm{~m}^{2} \mathrm{e} 1,50 \mathrm{~m}^{2}$, respectivamente quando consorciada com o arroz $\mathrm{e}$ o milho. Consorciada com o sorgo e o milheto, os seus IAF foram ainda menores. Na mesma data, 70 dias após a emergência, alcançou $1,12 \mathrm{~m}^{2}$ consorciada com sorgo, e $0,27 \mathrm{~m}^{2}$ quando consorciada com o milheto. Consorciada com essas culturas (sorgo e milheto), alcançou valores máximos também aos 82 dias. Consorciada, a braquiária antecipa o seu ciclo, o que pode ser constatado pelos seus IAF máximos alcançados aos 82 dias, diferentemente de quando solteira, que alcançou IAF máximo aos 117 dias. O gradual aumento no sombreamento causado pelas plantas dos cereais leva, presumivelmente, a um ineficiente suprimento de fotoassimilados, forçando a braquiária a antecipar seu ciclo.

O índice de área foliar ótimo é alcançado quando a taxa de crescimento da cultura (TCC) é máxima (Kvet et al., 1971). De acordo com essa definição, o IAF ótimo da braquiária solteira foi alcançado aos 97 dias, quando a TCC da massa seca total foi máxima $\left(371,7 \mathrm{~kg} \mathrm{ha}^{-1} \mathrm{dia}^{-1}\right)$. E, no consórcio, os IAF ótimos da braquiária aconteceram simultaneamente aos 70 dias (Fig. 3)

Como, do total da massa da parte aérea (MST), as folhas são, normalmente, mais apreciadas pelos animais do que os colmos, para facilitar o manejo da pastagem é interessante verificar os IAF ótimos, em forrageiras, tomando como referência as TCC das folhas (Fig. 4). Nesse caso, os IAF ótimos tanto da braquiária solteira quanto da consorciada acontece-

TABELA 1. Coeficientes $(C, A$ e B $)$ da equação $Y=C \operatorname{EXP}\left(A X+B^{2}\right)$ ajustada aos dados de índice de área foliar (IAF), massa seca das folhas verdes (MSFV), dos colmos (MSC) e total (MST) em função do tempo (dias após a emergência) da braquiária solteira e consorciada e os respectivos coeficientes de determinação $(R)$, valores de $F$ e níveis de significância dos ajustes.

\begin{tabular}{llllllll}
\hline \multirow{2}{*}{ Variável } & Tratamento & \multicolumn{3}{c}{ Coeficientes da equação } & R & F & P \\
\cline { 3 - 5 } & & \multicolumn{1}{c}{$\mathrm{C}$} & $\mathrm{A}$ & $\mathrm{B}$ & & & \\
\hline IAF & Braq. solteira & $7,91.10^{-2}$ & $7,831.10^{-2}$ & $-3,387.10^{-4}$ & 0,93 & 15,8 & $<0,01$ \\
IAF & Braq. x milheto & 1,100 & $7,400.10^{-2}$ & $-4,300.10^{-4}$ & 0,94 & 11,7 & $<0,05$ \\
IAF & Braq. x milho & $6,200.10^{-3}$ & 0,143 & $-9,312.10^{-4}$ & 0,93 & 10,3 & $<0,05$ \\
IAF & Braq. x arroz & $5,6.10^{-4}$ & 0,195 & $-1,191.10^{-3}$ & 0,98 & 40,4 & $<0,01$ \\
IAF & Braq. x sorgo & 0,02 & $9,561.10^{2}$ & $-5,813.10^{-4}$ & 0,87 & 4,7 & $<0,10$ \\
MSFV & Braq. solteira & 2,557 & 0,087 & $-3,579.10^{-4}$ & 0,95 & 23,7 & $<0,01$ \\
MSFV & Braq. x milheto & $9,133.10^{-2}$ & 0,127 & $-7,720.10^{-4}$ & 0,96 & 73,5 & $<0,01$ \\
MSFV & Braq. x milho & 0,319 & 0,136 & $-8,471.10^{-4}$ & 0,97 & 20,7 & $<0,05$ \\
MSFV & Braq. x arroz & 0,023 & 0,197 & $-1,171.10^{-3}$ & 0,99 & 73,5 & $<0,01$ \\
MSFV & Braq. x sorgo & 0,578 & 0,111 & $-6,393.10^{-4}$ & 0,91 & 7,0 & $<0,10$ \\
MSC & Braq. solteira & 0,260 & 0,132 & $-4,930.10^{-4}$ & 0,98 & 71,1 & $<0,01$ \\
MSC & Braq. x milheto & $1,197.10^{-2}$ & 0,193 & $-1,202.10^{-3}$ & 0,98 & 48,4 & $<0,01$ \\
MSC & Braq. x milho & $6,810.10^{-2}$ & 0,165 & $-8,940.10^{-4}$ & 0,99 & 48,8 & $<0,01$ \\
MSC & Braq. x arroz & $2,240.10^{-3}$ & 0,249 & $-1,360.10^{-3}$ & 0,99 & 135,5 & $<0,01$ \\
MSC & Braq. x sorgo & $6,740.10^{-2}$ & 0,170 & $-9,470.10^{-4}$ & 0,96 & 16,1 & $<0,05$ \\
MST & Braq. solteira & 18,89 & 0,106 & $-3,94.10^{-4}$ & 0,98 & 60,2 & $<0,01$ \\
MST & Braq. x milheto & 0,60 & 0,163 & $-1,010.10^{-3}$ & 0,98 & 35,0 & $<0,01$ \\
MST & Braq. x milho & 3,76 & 0,143 & $-8,032.10^{-4}$ & 0,98 & 35,8 & $<0,01$ \\
MST & Braq. x arroz & 0,19 & 0,214 & $-1,181.10^{-3}$ & 0,99 & 100,6 & $<0,01$ \\
MST & Braq. x sorgo & 3,07 & 0,139 & $-7,771.10^{-4}$ & 0,94 & 12,4 & $<0,05$ \\
\hline
\end{tabular}


ram antes. Os da solteira aconteceram aos 80 dias após a emergência, e os da consorciada entre 55 e 70 dias.

Os IAF da braquiária consorciada foram inferiores aos das culturas (cereais) no decorrer de todo o ciclo (Fig. 5), exceto quando consorciada com o arroz. A partir dos 82 DAE, os IAF da braquiária ultrapassaram os do arroz. Os menores IAF da fase inicial do arroz exerceram menor competição com a braquiária em relação às demais culturas, favorecendo-a, possivelmente por permitir maior penetração de luz. O IAF do arroz aos 39 dias era de 0,7 e do milho, milheto e sorgo, 1,7, 2,6 e 3,1, respectivamente (Fig. 5); além disso, na floração, o arroz pára de crescer, e, conseqüentemente, a quantidade de folhas amadurecendo é maior do que a de folhas verdes crescendo. Na braquiária isso aconteceu, mas

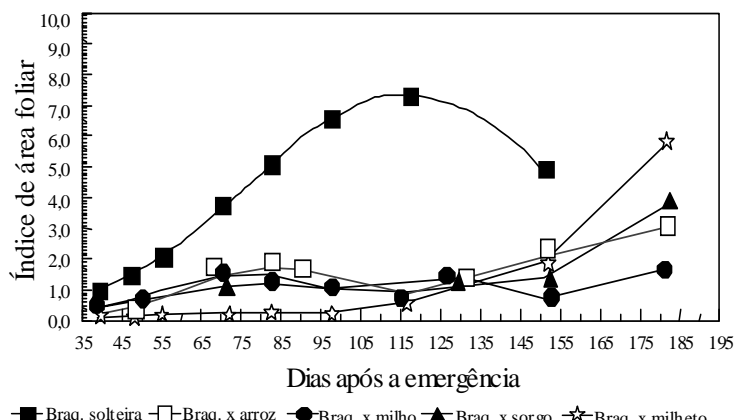

-Braq. solteira $\square-$ Braq. $x$ arroz - Braq. $x$ milho
FIG. 2. Evolucão do $x$ sorgo índice de área foliar $\left(\mathrm{m}^{2}\right.$ de folhas $\mathrm{m}^{-2}$ de terreno) da braquiária solteira e consorciada com arroz, milho, sorgo e milheto.

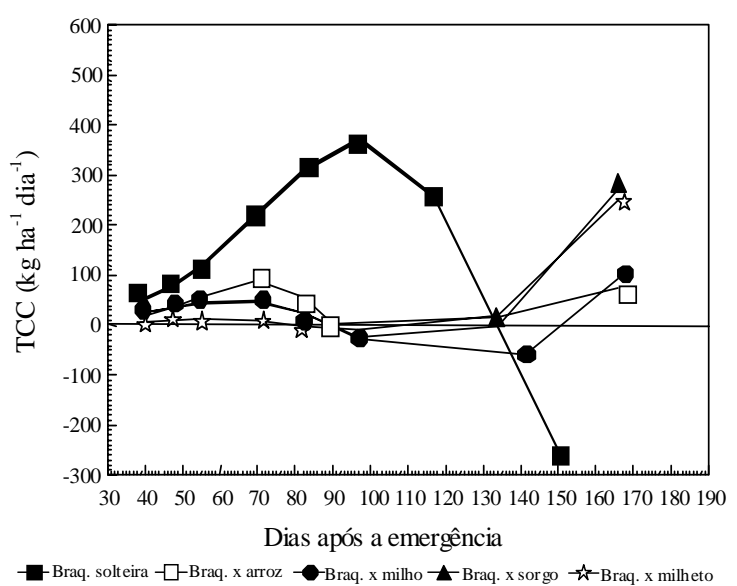

FIG. 3. Evolução das taxas de crescimento (TCC) da massa seca total da braquiária solteira e consorciada com milho, sorgo, milheto e arroz. numa proporção menor. Tem sido observado que em condições de lavoura, caso o arroz não seja colhido na época correta, a braquiária o domina, tornandolhe inviável a colheita.

O milheto é uma planta precoce que após os 39 dias, data da primeira amostragem, apresentou declínio nos seus IAF, tendo, portanto, já passado pelo seu IAF máximo, mas continuou produzindo novos perfilhos e folhas, mantendo valores de IAF superiores a um, até a época da colheita (Fig. 5). Embora não tenha apresentado IAF maior do que o do sorgo, o milheto foi mais competitivo. É possível que, por ter apresentado IAF máximo antes do sorgo, tenha inibido fortemente o crescimento inicial da braquiária pelo sombreamento excessivo, com repercussão no restante do ciclo da forrageira.

O milho apresentou crescimento um tanto atípico do seu IAF dos 82 para os $97 \mathrm{DAE}$, aparentemente sem explicação, embora possam ter acontecido problemas de amostragem, em virtude da heterogeneidade das plantas (Fig. 5).

Produção de massa seca pela braquiária solteira e consorciada

A massa seca total da parte aérea (MST) da braquiária solteira cresceu até os 117 dias, chegando a $19.580 \mathrm{~kg} \mathrm{ha}^{-1}$, estabilizando-se a partir de então (Fig. 6). Consorciada com os cereais, a braquiária sofreu forte competição, de modo que a sua MST

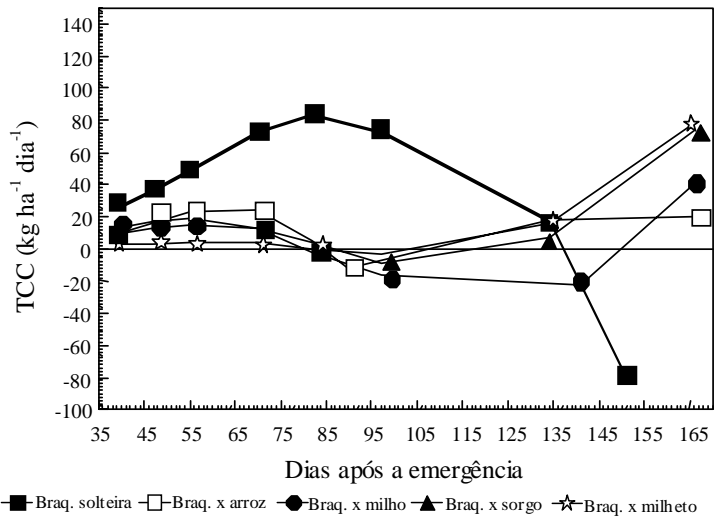

FIG. 4. Evolução das taxas de crescimento (TCC) da massa seca das folhas verdes da braquiária solteira e consorciada com milho, sorgo, milheto e arroz. 
não ultrapassou os $3.000 \mathrm{~kg} \mathrm{ha}^{-1}$ ao longo do seu ciclo de desenvolvimento. O arroz competiu menos. Consorciada com ele, a braquiária alcançou MST de $2.991 \mathrm{~kg} \mathrm{ha}^{-1}$ aos 90 dias. Intermediariamente, competiram o sorgo e o milho. Com o sorgo, a braquiária alcançou MST de $1.934 \mathrm{~kg} \mathrm{ha}^{-1}$ aos 82 dias, estabilizando o seu crescimento; e com o milho, $2.536 \mathrm{~kg} \mathrm{ha}^{-1}$ na mesma data, para então estabilizar-se. $\mathrm{O}$ milheto foi o mais competitivo. Com ele, a braquiária alcançou MST máxima de apenas 422,6 $\mathrm{kg} \mathrm{ha}^{-1}$, aos 82 dias após a emergência.

A produção de massa seca de folhas (MSFV) pela braquiária consorciada (Fig. 7) não ultrapassou $1.000 \mathrm{~kg} \mathrm{ha}^{-1} \mathrm{em}$ nenhuma das avaliações até a colheita das culturas. A braquiária solteira alcançou $1.922 \mathrm{~kg} \mathrm{ha}^{-1}$ aos 70 dias, e produção máxima de $5.035 \mathrm{~kg} \mathrm{ha}^{-1}$ aos 117 dias após a emergência.

Quanto à massa seca dos colmos (MSC), alcançou $1.097 \mathrm{~kg} \mathrm{ha}^{-1}$ aos 70 dias quando consorciada com arroz, e menos de $1.000 \mathrm{~kg} \mathrm{ha}^{-1}$ quando consorciada com as demais culturas (Fig. 8). Solteira, a braquiária alcançou $2.374 \mathrm{~kg} \mathrm{ha}^{-1}$ aos 70 dias,
$9.045 \mathrm{~kg} \mathrm{ha}^{-1}$ aos 97 dias e produção de $15.180 \mathrm{~kg} \mathrm{ha}^{-1}$, por ocasião da última amostragem aos 151 dias após a emergência.

A braquiária solteira e consorciada com sorgo e com milheto alcançou valores máximos de massa seca das folhas na mesma data em que alcançou valores máximos de massa seca dos colmos. Consorciada com arroz e com milho, alcançou, primeiro, massa seca máxima de folhas (82 dias), para em seguida alcançar massa seca máxima de colmos. Isso significa que embora as folhas tenham paralisado o seu crescimento, elas continuaram suprindo os colmos, translocando para eles material fotossintetizado.

Após 150 dias, a braquiária solteira começou a senescer e a acamar, deixando de ser interessante continuar com a amostragem das plantas para análise.

\section{Relação folha/colmo}

Desde o início das amostragens (39 dias), observou-se gradual redução na relação folhas/colmo (MSFV/MSC) (Fig. 9). A melhor proporção foi obti-
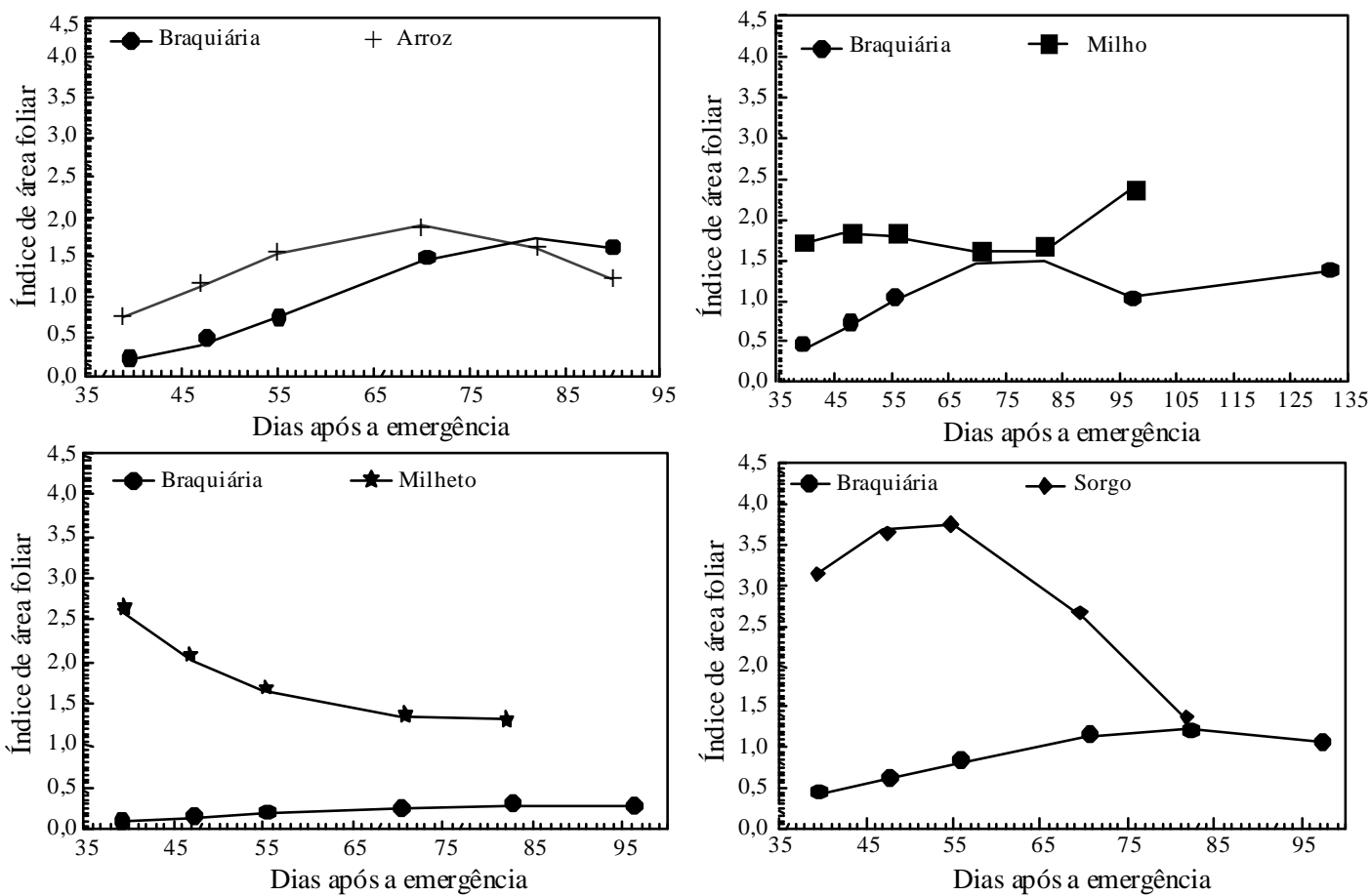

FIG. 5. Evolução dos índices de área foliar da braquiária e dos cereais arroz, milho, milheto e sorgo, com ela consorciados. 
da na braquiária solteira, aos 39 dias $(1,99)$, indicando partição preferencial de fotoassimilados ao desenvolvimento foliar, em detrimento do desenvolvimento dos colmos. Porém, a queda foi acentuada a partir da referida data. Por volta dos 82 dias, os valores, tanto para a braquiária solteira como para a consorciada, foram muito semelhantes, presumivelmente pela partição gradual e favorável de carboidratos em benefício dos colmos.

Taxas de crescimento da braquiária solteira e consorciada com as culturas

A taxa instantânea de crescimento (TCC) foi estimada até a colheita dos cereais, a partir das equa-

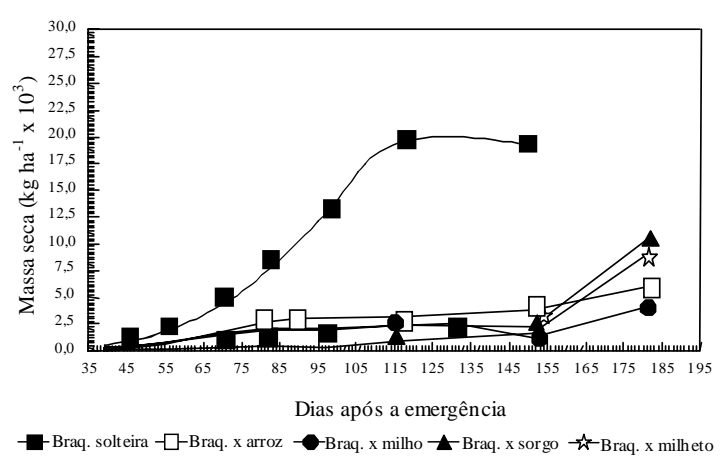

FIG. 6. Evolução, com a idade, da massa seca total da braquiária solteira e consorciada com arroz, milho, sorgo e milheto.

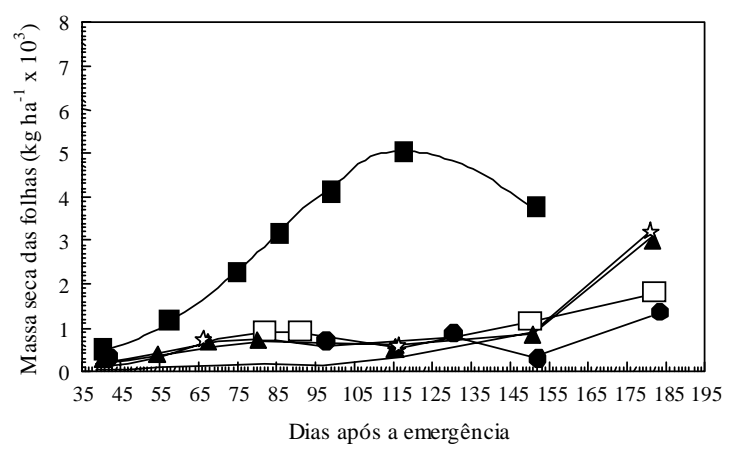

-Braq. solteira $-\square$-Braq. x arroz -Braq. x milho $\backslash$ - Braq. x sorgo - Braq. x milheto

FIG. 7. Evolução, com a idade, da massa seca das folhas verdes (MSFV) da braquiária solteira e consorciada com arroz, milho, sorgo e milheto. ções ajustadas, utilizando programa computacional (Portes \& Castro Júnior, 1991).

Quanto às taxas de crescimento da massa seca total da parte aérea (TCC), as da braquiária solteira aumentaram gradualmente, alcançando $222,8 \mathrm{~kg} \mathrm{ha}^{-1}$ aos 70 dias, continuando o crescimento até atingir um máximo de $371,7 \mathrm{~kg} \mathrm{ha}^{-1} \mathrm{dia}^{-1}$ aos 97 dias, caindo para 254,1 kg ha-1 dia $^{-1}$ aos 117 dias (Fig. 3). A partir desta data, a morte das suas folhas e colmos foi acentuada, culminando com uma taxa de crescimento negativo de $-269,1 \mathrm{~kg} \mathrm{ha}^{-1} \mathrm{dia}^{-1}$, aos 151 dias. Consorciada com o sorgo e o milho, a braquiária produziu taxas muito parecidas, de 45,4 e 47,6 $\mathrm{kg} \mathrm{ha}^{-1} \mathrm{dia}^{-1}$, respectivamente, aos 70 dias; consorciada com o arroz, obteve a maior taxa $\left(88,2 \mathrm{~kg} \mathrm{ha}^{-1} \mathrm{dia}^{-1}\right)$ aos 70 dias;

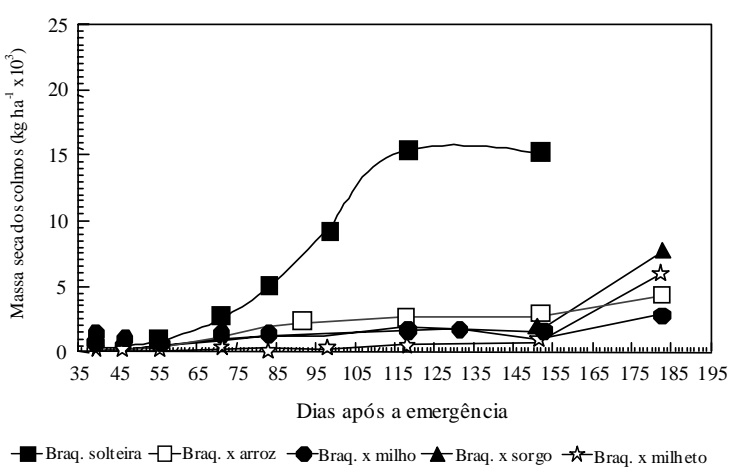

FIG. 8. Evolução, com a idade, da massa seca dos colmos da braquiária solteira e consorciada com arroz, milho, sorgo e milheto.

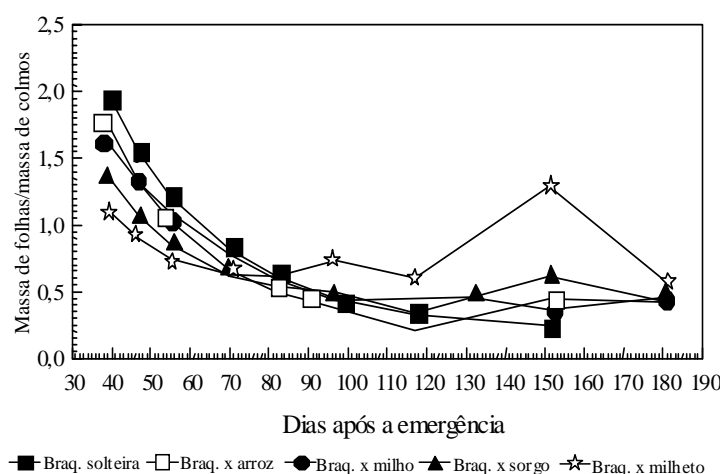

FIG. 9. Evolução da relação massa de folha/massa de colmos da braquiária solteira e consorciada com milho, sorgo, milheto e arroz.

Pesq. agropec. bras., Brasília, v.35, n.7, p.1349-1358, jul. 2000 
consorciada com o milheto, alcançou taxa máxima de $11,3 \mathrm{~kg} \mathrm{ha}^{-1} \mathrm{dia}^{-1}$, mais precocemente, aos 55 dias, isto é, a menor entre as taxas máximas. O milheto, portanto, foi a cultura que mais competiu com a braquiária, também em termos de produção de massa seca.

Observa-se, na Fig. 4, que aos 82 dias a braquiária solteira alcançou a maior taxa de crescimento das folhas (82,9 kg ha-1 $\left.\mathrm{dia}^{-1}\right)$, caindo em seguida; consorciada com o milho, alcançou taxa máxima aos 55 dias $\left(18,8 \mathrm{~kg} \mathrm{ha}^{-1} \mathrm{dia}^{-1}\right)$; consorciada com o sorgo e o milheto, também aos 55 dias, respectivamente, 14,8 e 3,9 $\mathrm{kg} \mathrm{ha}^{-1} \mathrm{dia}^{-1}$; e com o arroz, a taxa máxima se deu aos 70 dias após a emergência $\left(24,4 \mathrm{~kg} \mathrm{ha}^{-1} \mathrm{dia}^{-1}\right)$.

Aos 39 dias, as taxas de crescimento das folhas foram maiores do que as de colmos na braquiária solteira e na consorciada com milho e arroz (Figs. $4 \mathrm{e}$ 10); foram menores, consorciadas com sorgo e milheto. Excluindo esta data, 39 dias, quando houve taxas de crescimento de folhas maiores do que o de colmos, nas demais datas predominaram maiores taxas de crescimento dos colmos em relação às taxas de crescimento das folhas. Isto significa que na partição de fotoassimilados houve maior direcionamento de carboidratos para a produção de colmos do que para a produção de folhas. Tratando-se de capim, o contrário seria preferível, visto que as folhas são preferidas pelos animais consumidores.

As quedas bruscas observadas nas taxas de crescimento das folhas e dos colmos da braquiária solteira a partir dos 82 e 97 dias, respectivamente, mostradas nas Figs. 4 e 10, significam que esses órgãos

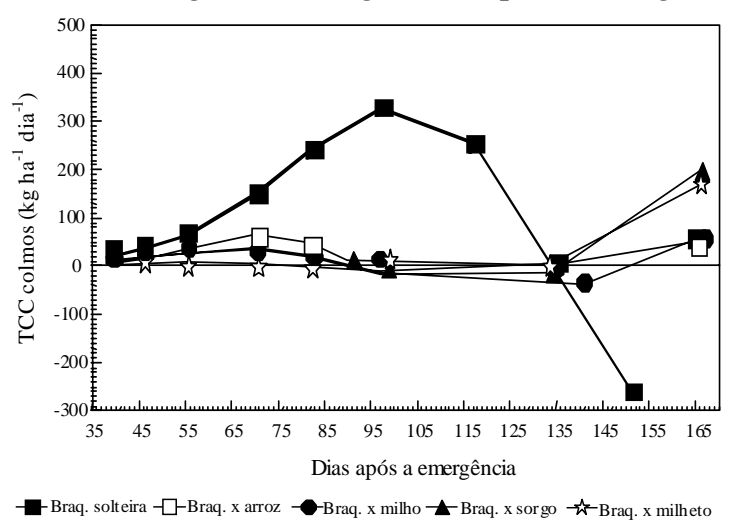

FIG. 10. Evolução das taxas de crescimento da massa seca dos colmos da braquiária solteira e consorciada com milho, sorgo, milheto e arroz. (folhas e colmos) estão sendo produzidos, e crescendo, mas menos acentuadamente do que até as referidas datas. Os valores negativos acima dos 135 dias indicam que as folhas e colmos estão amadurecendo mais rapidamente do que sendo produzidos.

Produtividades de grãos pelas culturas

Dos cereais consorciados com a braquiária foram obtidas as seguintes produtividades médias de grãos por hectare: do milho, $3.583 \mathrm{~kg}$; do sorgo, $2.241 \mathrm{~kg}$; do milheto, $1.261 \mathrm{~kg}$, e do arroz, $2.567 \mathrm{~kg}$.

A produtividade de grãos no sistema de consórcio é, normalmente, inferior em relação ao monocultivo. Em experimento realizado com arroz no município de Guapó, GO (Portes et al., 1995) a variedade Douradão Precoce, de ciclo curto (em torno de 110 dias), teve $40 \%$ de redução na produtividade, e a Rio Paranaíba, de ciclo médio - em torno de 140 dias -, teve redução de, aproximadamente, 50\%. Normalmente, a redução nas produtividades varia de cultura para cultura. As culturas de maior porte, como milho, sorgo e milheto, são menos afetadas, provavelmente por não sofrerem tão intensamente 0 efeito do sombreamento, como sofrem as culturas de menor porte.

\section{Segunda fase: da colheita das culturas e poda da braquiária até a sua recuperação}

A segunda fase do experimento, que se iniciou após a colheita dos cereais (aos 102 dias após a emergência do arroz, sorgo e milheto e aos 131 dias do milho), evidenciou, nos primeiros dias, uma aparente paralisação no crescimento da braquiária, da colheita aos 151 DAE. No corte da braquiária, por ocasião da colheita dos cereais, a maior parte das suas folhas foi eliminada, permanecendo grande parte dos colmos. Porém, mesmo tendo a branquiária sofrido o corte ela ainda apresentava 544,1, 616,2, 342,6 e 786,0 $\mathrm{kg} \mathrm{ha}^{-1}$ de massa seca de folhas e $2657,0,1825,0$, 567,0 e $1701,0 \mathrm{~kg} \mathrm{ha}^{-1}$ de massa seca de colmos, após a colheita do arroz, sorgo, milheto e milho, respectivamente. Durante a aparente paralisação do crescimento, poderia estar ocorrendo a realocação de fotoassimilados desses colmos para a formação de novos perfilhos e folhas (Figs. 2 e 11). O crescimento da massa seca total é reassumido quando essas fo- 
lhas passam a suprir a planta (Fig. 6). O maior número de perfilhos aos 181 dias após a emergência ocorreu com a braquiária após a colheita do milheto, alcançando 462 perfilhos $\mathrm{m}^{-2}$; e na seqüência, após a colheita do arroz, sorgo e milho, alcançando 222, 405 e 183 perfilhos $\mathrm{m}^{-2}$, respectivamente (Fig. 11).

Os valores dos índices de área foliar e da massa seca total da parte aérea da braquiária após a colheita do arroz foram sempre maiores do que no local onde foi colhido o milho. Diferentemente, após a colheita do milheto, a braquiária apresentou IAF maior do que após a colheita do sorgo, mas massa seca total menor (Figs. 2 e 6). Com o milheto, a braquiária sofreu forte competição, maior do que quando consorciada com o sorgo. Houve, porém, após a colheita do milheto, uma tendência da braquiária de recuperar a sua área foliar mais rapidamente, aparentemente tornando-a melhor preparada para produzir fotoassimilados e recuperar-se mais rapidamente.

Em todos os tratamentos houve incrementos na massa seca total da parte aérea, na massa seca de folhas verdes, e na massa seca de colmos.

Até a colheita dos cereais, as taxas de crescimento da braquiária foram calculadas derivando-se as equações obtidas em relação ao crescimento da massa seca em função do tempo (DAE). São, portanto, taxas instantâneas de crescimento. Após a colheita dos cereais, em decorrência do baixo número de pares de dados, insuficientes para se conseguir um bom ajuste, utilizou-se, para o cálculo das taxas de crescimento da rebrota da braquiária, a fórmula deduzida, tradicional, resultando, portanto, em taxas médias de crescimento (Radford, 1967).

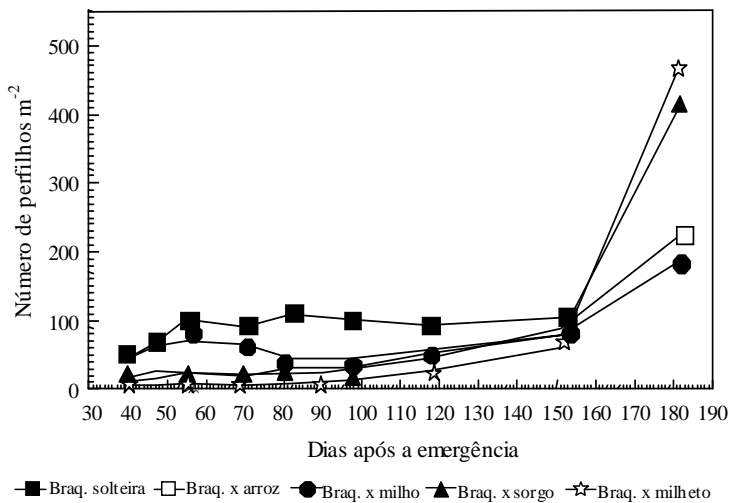

FIG. 11. Número de perfilhos da braquiária solteira e consorciada com milho, sorgo, milheto e arroz.
As taxas médias de crescimento (TCC médias), entre o 49ㅇ e o 79을 dia após a colheita do sorgo, milheto e arroz, e entre o 20 ㅇ e 50 을 dia após a colheita do milho (151으 e o 181ํ dia após emergência), foram de 270,2, 246,8, 73,7 e 92,2 $\mathrm{kg} \mathrm{ha}^{-1} \mathrm{dia}^{-1}$, respectivamente (Fig. 3). Já as TCC médias das folhas verdes foram de 73,3, 77,7, 20,2 e 40,0 kg ha-1 $\mathrm{dia}^{-1}$ (Fig. 4); e as de colmos, 197,0, 169,1, 53,2 e $61,2 \mathrm{~kg} \mathrm{ha}^{-1} \mathrm{dia}^{-1}$, nas mesmas datas (Fig. 10). As TCC médias da rebrota de folhas de 40,0 e $20,2 \mathrm{~kg} \mathrm{ha}^{-1} \mathrm{dia}^{-1}$, obtidas após a colheita do milho e do arroz, respectivamente, são ainda baixas, sendo recomendável aguardar um pouco mais para utilizálas como pastagem. As taxas médias de crescimento da rebrota de folhas da braquiária, de 73,3 e $77,7 \mathrm{~kg} \mathrm{ha}^{-1} \mathrm{dia}^{-1}$ entre o 49ㅇ e o 79을 dia após a colheita do sorgo e do milheto, são parecidas com as da braquiária solteira aos 70 a 80 dias, ideais, portanto, para serem utilizadas (Kluthcouski et al., 1991). Segundo esses autores, após a colheita das culturas a área reformada pelo Sistema Barreirão deve ser vedada ao pastejo por pelo menos 60 dias, para a forrageira produzir boa quantidade de folhas.

Setenta e nove dias após a colheita (DAC) do arroz, sorgo, milheto, e 50 dias após a colheita do milho (181 dias após a emergência), a massa seca total da parte aérea da braquiária (Fig. 6) alcançou, respectivamente, $6.020,0,10.397,6,8.989,0 \mathrm{e}$ $4.055,0 \mathrm{~kg} \mathrm{ha}^{-1}$. A quantidade obtida de massa seca de folhas verdes de braquiária nas mesmas datas foi de $1.772,2,3.065,5,3.224,0$ e $1.268,0 \mathrm{~kg} \mathrm{ha}^{-1}$, respectivamente (Fig.7), e a quantidade de massa seca dos colmos foi de 4.247, 9, 7.332,1,5.765,0, e 2.787,0 $\mathrm{kg} \mathrm{ha}^{-1}$, com proporções entre massa seca de folhas/massa seca de colmos de $0,417,0,418,0,559$, e 0,455 , respectivamente (Fig. 9). A melhor relação de folhas/colmos foi, portanto, para a braquiária após a colheita do milheto $(0,559)$.

Por apresentar ciclo mais longo, o milho foi colhido mais tardiamente. Tal fato prolongou a sua competição com a braquiária, por isso a menor produção de massa pela forrageira após a sua colheita.

\section{CONCLUSÕES}

1. A consorciação dos cereais milho, sorgo, milheto e arroz com a Brachiaria brizantha 
cv. Marandu é um sistema viável do ponto de vista agronômico, e pode ser utilizada em reimplantação de pastagens degradadas.

2. A presença dos cereais afeta severamente o crescimento da braquiária; mas com a sua rebrota após a colheita dos cereais, sua recuperação é rápida.

3. A rebrota rápida da braquiária permite que a pastagem seja utilizada aos 70 dias após a colheita dos cereais.

\section{REFERÊNCIAS}

KLUTHCOUSKI, J.; PACHECO, A.P.; TEIXEIRA, S.M.; OLIVEIRA, E.T. de. Renovação de pastagem de cerrado com arroz. I. Sistema Barreirão. Goiânia : Embrapa-CNPAF, 1991. 20p. (EmbrapaCNPAF. Documentos, 33)

KVET, J.; ONDOK, J.P.; NECAS, J.; JARVIS, P.G Methods of growth analysis. In: SESTAK, Z; CATSKY, J.; JARVIS, P.G. (Ed.). Plant photosynthetic production: manual of methods. The Hague : W. Junk, 1971. p.343-391.

MACEDO, J. Os cerrados brasileiros: alternativas para a produção de alimentos no limiar do século XXI. Revista de Política Agrícola, São Paulo, v.4, n.2, p.11-18, 1995.

MACEDO, M.C.; ZIMMER, A.H. Sistema planta/lavoura e seus efeitos na produtividade agropecuária. In SIMPÓSIO SOBRE ECOSSISTEMA DE PASTA-
GEM, 2., 1993, Jaboticabal. Anais. Jaboticabal FUNEPE/UNESP, 1993. p.216-245.

OLIVEIRA, I.P. de; KLUTHCOUSKI, J.; YOKOYAMA, L.P.; DUTRA, L.G.; PORTES, T. de A.; SILVA, A.E. da; PINHEIRO, B. da S.; FERREIRA, E.; CASTRO, E. da M. de. Sistema Barreirão: recuperação/renovação de pastagens degradadas em consórcio com culturas anuais. Goiânia : Embrapa-CNPAF, 1996 90p. (Embrapa-CNPAF. Documentos, 64).

PORTES, T. de A.; CASTRO JÚNIOR, L.G. de. Análise de crescimento de plantas: um programa computacional auxiliar. Revista Brasileira de Fisiologia Vegetal, Londrina, v.3, n.1, p.53-56, 1991.

PORTES, T. de A.; OLIVEIRA, I.P. de; DUTRA, L.G.; KLUTHCOUSKI, J. Competição entre capim braquiária e cereais consorciados no Sistema Barreirão. Goiânia : Embrapa-CNPAF, 1995. 10p. (Embrapa-CNPAF. Comunicado Técnico, 25).

RADFORD, P.J. Growth analysis formulae: their use and abuse. Crop Science, Madison, v.7, n.3, p.171-175, 1967.

YOKOYAMA, L.P.; KLUTHCOUSKI, J.; OLIVEIRA, I.P. de. Impactos socioeconômicos da tecnologia "Sistema Barreirão". Santo Antônio de Goiás : Embrapa-CNPAF, 1998. 37p. (Embrapa-CNPAF. Boletim de Pesquisa, 9).

ZULlo JÚNIOR, J.; ARRUDA, F.B. Programa computacional para ajuste de equações em dados experimentais. Campinas : Instituto Agronômico, 1987. 31p. (IAC. Boletim Técnico, 113). 